\title{
Intraoperative radiotherapy with low-energy $x$-rays after neurosurgical resection of brain metastases_-an Augsburg University Medical Center experience
}

\author{
Klaus-Henning Kahl' ${ }^{1}$ D - Nikolaos Balagiannis' ${ }^{1}$ Michael Höck ${ }^{1}$ Sabine Schill² Zoha Roushan $^{2}$ Ehab Shiban ${ }^{3}$. \\ Heiko Müller ${ }^{3}$ Ute Grossert ${ }^{3}$ - Ina Konietzko ${ }^{3}$ Björn Sommer ${ }^{3}$ Christoph J. Maurer ${ }^{4}$ Ansgar Berlis ${ }^{4}$. \\ Volkmar Heidecke ${ }^{3}$ Tilman Janzen² • Georg Stüben ${ }^{1}$
}

Received: 24 March 2021 / Accepted: 18 July 2021 / Published online: 20 August 2021

(c) The Author(s) 2021

\begin{abstract}
Purpose External-beam radiotherapy (EBRT) is the predominant method for localized brain radiotherapy (LBRT) after resection of brain metastases (BM). Intraoperative radiotherapy (IORT) with 50-kV x-rays is an alternative way to focally irradiate the resection cavity after BM surgery, with the option of shortening the overall treatment time and limiting normal tissue irradiation.

Methods We retrospectively analyzed the outcomes of all patients who underwent neurosurgical resection of BM and 50-kV x-ray IORT between 2013 and 2020 at Augsburg University Medical Center.

Results We identified 40 patients with 44 resected BM treated with 50-kV x-ray IORT. Median diameter of the resected metastases was $2.8 \mathrm{~cm}$ (range $1.5-5.9 \mathrm{~cm}$ ). Median applied dose was $20 \mathrm{~Gy}$. All patients received standardized follow-up (FU) including 3-monthly MRI of the brain. Mean FU was 14.4 months, with a median MRI FU for alive patients of 12.2 months. Median overall survival (OS) of all treated patients was 26.4 months (estimated 1-year OS 61.6\%). The observed local control (LC) rate of the resection cavity was 88.6\% (estimated 1-year LC 84.3\%). Distant brain control (DC) was $47.5 \%$ (estimated 1-year DC 33.5\%). Only $25 \%$ of all patients needed WBI in the further course of disease. The observed radionecrosis rate was $2.5 \%$.

Conclusion IORT with 50-kV x-rays is a safe and appealing way to apply LBRT after neurosurgical resection of BM, with low toxicity and excellent LC. Close MRI FU is paramount to detect distant brain failure (DBF) early.
\end{abstract}

Keywords IORT $\cdot$ Radionecrosis $\cdot$ Local control $\cdot$ Postoperative $\cdot$ Cavity boost

Klaus-Henning Kahl, MD

klaushenning.kahl@uk-augsburg.de

Georg Stüben, MD

georg.stueben@uk-augsburg.de

1 Klinik für Strahlentherapie und Radioonkologie, Universitätsklinikum Augsburg,

Stenglinstraße 2, 86156 Augsburg, Germany

2 Medizinische Physik und Strahlenschutz, Universitätsklinikum Augsburg, Augsburg, Germany

3 Klinik für Neurochirurgie, Universitätsklinikum Augsburg, Augsburg, Germany

4 Klinik für Diagnostische und Interventionelle Radiologie und Neuroradiologie, Universitätsklinikum Augsburg, Augsburg, Germany

\section{Introduction}

In recent decades, improved systemic treatment options have led to prolonged survival of patients suffering from metastatic cancer of many tumor entities (e.g., malignant melanoma, colorectal carcinoma, lung cancer), including patients with BM. In the early 1990s, the median survival of highly selected patients treated with resection of single BM and whole-brain radiotherapy (WBI) was 9.2 months [1]. In recent series of patients undergoing surgery and focal radiotherapy for BM, median survival even exceeds 24 months $[2,3]$. As the majority of these patients live longer than 1 year after BM treatment, long-term LC and treatmentrelated long-term neurotoxicity have gained increasing importance. Several trials have shown the detrimental effect of WBI on neurocognitive functioning [4-8]. This led to 
a shift of paradigm in radiotherapy treatment after resection of BM, away from WBI and towards focal irradiation of the resection cavity [9, 10]. Most of this LBRT is administered via EBRT, either as stereotactic radiosurgery (SRS) or as hypofractionated stereotactic radiotherapy (HSRT) [11]. IORT with $50-\mathrm{kV}$ x-rays is an alternative method to irradiate the resection cavity focally after neurosurgical resection of BM [12]. Since 2013, we have treated patients with IORT after neurosurgical BM resection on an individual case-bycase treatment decision basis, always after discussion at and interdisciplinary consensus of the multidisciplinary tumor board (MTB). An expert panel of the German Society for Radiation Oncology (DEGRO) considered IORT after resection of BM as standard of care in the year 2017 [Expert panel decision DEGRO, inquiry 123, 17.02.2017]. Since then, the Augsburg University Medical Center (UKA) has run a program offering IORT to patients routinely scheduled for brain metastasectomy as an alternative to postoperative external-beam LBRT. A mean of 196 patients (SD 16 patients) were treated annually for BM at UKA in the past 3 years (2018-2020). Most of these patients (mean $88.5 \%$, SD 1.4\%) were treated with EBRT only, either with WBI or SRS/HSRT. A mean of 24 patients per year (SD 4 patients) were treated with a neurosurgical metastasectomy in this time period. Of those patients, approximately $38 \%$ were treated with IORT, all others with postoperative focal HSRT to the resection cavity.

\section{Materials and methods}

We conducted a retrospective analysis of all patients who were treated with IORT after neurosurgical resection of BM between 2013 and 2020 at UKA. We identified all patients from our oncology information system MOSAIQ (ELEKTA AB, Stockholm, Sweden) and gained additional information via the hospital information system ORBIS (DEDALUS Healthcare Group AG, Bonn, Germany) and the radiology information and picture archiving and communication system DeepUnity (DEDALUS Healthcare Group AG). The timepoint for the last FU included in this analysis was February 5, 2021.

Treatment of all cases followed the recommendations of the UKA multidisciplinary tumor board (MTB). With regard to patient section, a minimal distance of $5 \mathrm{~mm}$ between the border of the contrast-enhancing lesion in MRI and the optic tract/brainstem was mandatory. Patients with a history of small-cell lung cancer were excluded. Depending on the decision of the neurosurgeon, some but not all patients with centrally located metastases or metastases in the posterior fossa were excluded. After informed consent of the patient, neurosurgical brain metastasectomy was performed, and a frozen section to confirm malignancy of the removed tumor was prepared. Hereafter, the resection cavity was irradiated with 50-kV x-rays via an INTRABEAM system (ZEISS MEDITEC AG, Oberkochen, Germany) equipped with spherical applicators. The device and procedure have been described previously [12, 13]. Spherical applicator sizes of this IORT system range from 15 to $50 \mathrm{~mm}$ in diameter in 5-mm increments. The suitable applicator size was chosen by the neurosurgeon and radio-oncologist according to the size of the resection cavity, providing direct contact of the cavity walls to the surface of the applicator. Radiation dose was prescribed to the surface of the applicator (tissue depth $0 \mathrm{~mm}$ ), corresponding to the target volume/dose concept of postoperative SRS cavity treatment (GTV = CTV = cavity). Due to the dose distribution of the system, a 2-mm rim around the cavity received between $63 \%$ and $84 \%$ of the prescribed dose, depending on the size of the applicator. The applied dose was reduced to $38-53 \%$ at $5 \mathrm{~mm}$ and $18-32 \%$ at $10 \mathrm{~mm}$ tissue depth. After IORT, the applicator was removed and surgery was completed. After

Table 1 Patient and disease characteristics

\begin{tabular}{|c|c|}
\hline \multicolumn{2}{|l|}{ Patients characteristic } \\
\hline Number of patients & 40 \\
\hline Male/female & $18 / 22$ \\
\hline Patients alive & 24 \\
\hline Median age (range) & $\begin{array}{l}62.8 \text { years } \\
(39-83 \text { years })\end{array}$ \\
\hline Patients with previous brain RT & 4 \\
\hline Patients with metastases in other organs & 24 \\
\hline \multicolumn{2}{|l|}{$R P A$} \\
\hline Class 1 & 6 \\
\hline Class 2 & 31 \\
\hline Class 3 & 3 \\
\hline \multicolumn{2}{|l|}{ Lesion characteristics } \\
\hline Median number of BM at treatment (range) & $1(1-6)$ \\
\hline Median size of treated lesion (range) & $2.8 \mathrm{~cm}(1.5-5.9 \mathrm{~cm})$ \\
\hline Median size of applicator (range) & $2.0 \mathrm{~cm}(1.5-4.0 \mathrm{~cm})$ \\
\hline Median dose (range) & 20 Gy (13.4-20 Gy) \\
\hline Suspected incomplete resection in MRI & 14 \\
\hline \multicolumn{2}{|l|}{ Location of brain metastases } \\
\hline Frontal & 13 \\
\hline Parietal & 8 \\
\hline Occipital & 12 \\
\hline Temporal & 5 \\
\hline Posterior fossa & 6 \\
\hline \multicolumn{2}{|l|}{ Histology of resected metastases } \\
\hline NSCLC & 14 \\
\hline Breast cancer & 8 \\
\hline Melanoma & 7 \\
\hline Colorectal carcinoma & 6 \\
\hline Renal cell carcinoma & 3 \\
\hline $\begin{array}{l}\text { Other (Ovarian cancer/parotid cancer/bladder } \\
\text { cancer/esophageal cancer) }\end{array}$ & 6 \\
\hline
\end{tabular}


treatment, all patients received standardized FU including 3-monthly MRI of the brain, according to UKA FU policy for LBRT. All statistical analyses were performed with EZR (Version 3.4.1/The R Foundation for statistical computing, Vienna, Austria) [14] using Kaplan-Meier methods and log-rank tests.

\section{Results}

We identified 40 patients (22 female/18 male) with 44 resected BM who had been treated with $50-\mathrm{kV}$ x-ray IORT. For patients characteristics see Table 1. Median age of these patients at time of treatment was 62.8 years (range 29-83 years). Most patients fitted to recursive partitioning analysis (RPA) [15] class 2 (31 patients; class 1: 6 patients; class 3: 3 patients). Median diameter of the resected metastases was $2.8 \mathrm{~cm}$ (range $1.5-5.9 \mathrm{~cm}$ ). Median applied dose was 20Gy (range 13.4-20Gy). Four patients had a history of previous EBRT in the area of resection. All other patients were newly diagnosed with BM prior to resection. Median number of BM at treatment time was one (range 1-6). Maximum number of IORT procedures per patient was two. All other non-resected brain lesions were treated with stereotactic radiotherapy (SRS) with the exception of one patient receiving additional WBI. The predominant histology of the resected metastases was nonsmall-cell lung cancer (14 metastases), followed by breast cancer ( 8 metastases) and malignant melanoma ( 7 metastases). Twenty-four of these patients were simultaneously suffering from additional tumor burden in organs other than brain. After treatment, all patients received standardized

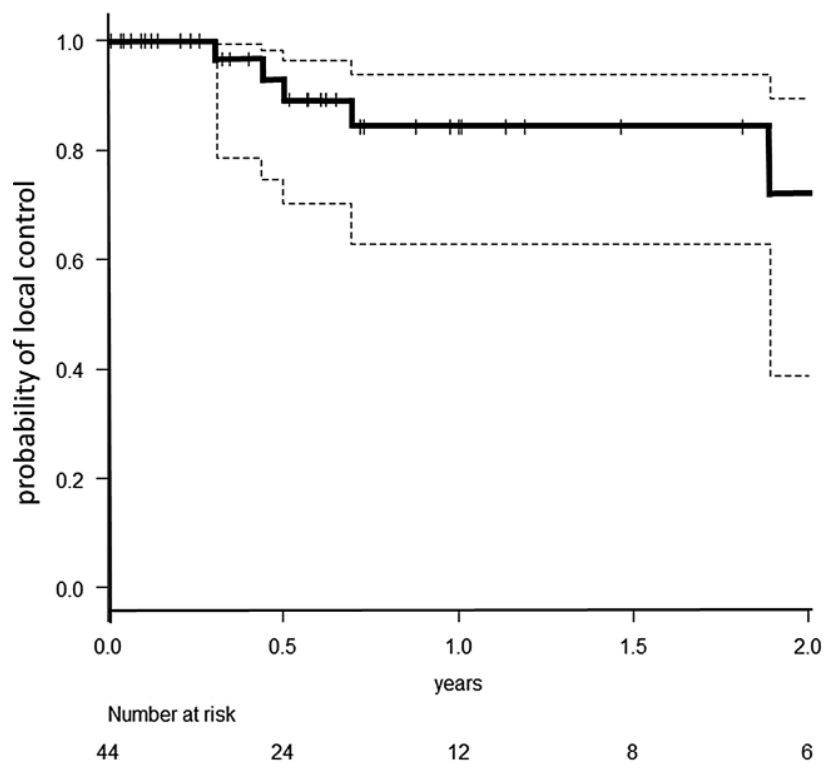

Fig. 1 Probability of local control after resection of BM and IORT (the dotted lines represent the $95 \%$ confidence intervals) follow-up (FU) including 3-monthly MRI of the brain according to UKA FU policy for LBRT. Mean follow-up was 14.4 months (SD: 18.1 months), with a median MRI followup for alive patients of 12.2 months (range 0-58.1 months). At the time of this analysis, 16 of these 40 patients had died. Median overall survival of all treated patients was 26.4 months (range 0.5-73.0 months), with an estimated overall survival at 1 year of $61.6 \%$. The observed local control (LC) rate of the resection cavity was $88.6 \%$, with estimated LC of $84.3 \%$ at 1 year (Fig. 1). All recurrences except one were histologically proven (NSCLC, breast cancer, malignant melanoma, ovarian cancer). Observed distant brain control (DC) was $47.5 \%$ with estimated DC of $33.5 \%$ at 1 year, including 4 patients $(10 \%)$ who developed leptomeningeal disease (LMD). The estimated LMD rate was $16.2 \%$ at 2 years. Only $25 \%$ of all patients received WBI in the further course of disease to achieve DC. All other patients could be salvaged via focal treatment. IORT did not increase the perioperative toxicity of brain surgery. Thirtyday mortality of the 44 interventions was $4.5 \%$, not related to IORT. One patient died from sepsis arising of the genitourinary tract and one patient suffered a lethal infarction of the middle cerebral artery 12 days postoperatively. One postoperative bleeding, one postoperative formation of a hygroma, and one wound infection in the area of the craniotomy were observed. One IORT procedure in the posterior fossa had to be terminated prematurely (applied 13.4 Gy of planned $18 \mathrm{~Gy}$ ) due to detection of an air embolism, which could be treated without consequential damage for the patient. Mean time from surgery to discharge from hospital was 7 days (range 2-27 days). The IORT procedure prolonged OR time by a mean of $25 \mathrm{~min}$ (range $15-42 \mathrm{~min}$ ). Mean operation time including IORT was $166 \mathrm{~min}$ (range 97 to $308 \mathrm{~min}$ ). Mean radiation time was 14:55 min (range 8:13-27:04 min). Twenty-four patients in this series needed systemic treatment due to additional tumor burden in other organs. Median time to start of systemic treatment after surgery was 18 days (range 0 to 130 days) for these patients. Brain necrosis of any grade after IORT was observed and histologically proven in one single, symptomatic case of a lesion in a pre-irradiated area only (observed brain necrosis rate $2.5 \%$ /estimated brain necrosis rate of $6.7 \%$ at 1 year). None of the non-pre-irradiated patients experienced radiologic signs of brain necrosis.

\section{Discussion}

To our knowledge, this is the largest published mono-institutional series of patients treated with IORT after resection of BM. In contrast to previous publications in this field $[12,13]$ reporting mainly LC/DC and toxicity data, we report a wider scope of the implementation of IORT in the 
treatment of patients with BM and its impact on multidisciplinary care. In 2013, we started treating patients with IORT after neurosurgical BM resection on an individual case-by-case treatment decision basis after interdisciplinary discussion and decision in the MTB. With increasing evidence for this procedure [12], this treatment is offered routinely to patients planned for resection of BM after MTB recommendation at the UKA as an optional treatment, replacing postoperative external beam LBRT in close to $40 \%$ of these patients in the last 3 years of the analyzed period. From the patients' perspective, this is an attractive option, as it is a "one-stop shop" with no further necessity of adjuvant radiotherapy after discharge from hospital. The observed LC in our series is definitively in the upper range of data reported after brain metastasectomy [3, 16-24]. When we started using IORT for LBRT in 2013, we applied lower doses of $16 \mathrm{~Gy}$ according to the Cleveland protocol [12]. After publication of the toxicity data of the INTRAGO phase1/2 study [25], we increased the dose in a stepwise manner and, since 2016, all patients have been irradiated with $20 \mathrm{~Gy}$. Other centers nowadays apply even higher doses [13, 25, 26]. However, with the reported outcome of our patients, we do not currently see a necessity for further dose escalation. Additionally, it has to be taken into account that the relative biological efficacy (RBE) of the applied low-energy x-rays (LEX) lies between 1.3 and 1.5 [27-29]. This means that $1 \mathrm{~Gy}$ applied with $50-\mathrm{kV}$ x-rays is biologically iso-equivalent to 1.3 to $1.5 \mathrm{~Gy}$ applied with photons (RBE 1). This makes 20 Gy of LEX IORT biologically iso-equivalent to 26 to $30 \mathrm{~Gy}$ of 6-MV photon SRS [30].

Within the IORT procedure, the choice of the optimally sized applicator and its correct placement in the resection cavity is of high importance. The applicator must fit into the cavity, providing direct contact of the cavity walls to the surface of the applicator. The treated volume around the resection cavity receiving a therapeutic dose encompasses a seam of tissue of only 5 to $10 \mathrm{~mm}$ at maximum [31, 32]. Due to the steep dose gradient of LEX, the choice of an applicator which is smaller than cavity size will result in underdosage of parts of the cavity. Applicator sizes bigger than the cavity space may cause harm to brain tissue by mechanical pressure. For the same reasons, optimal placement of the applicator within the cavity is also a key issue. This is based on the experience of the neurosurgeon only and his knowledge of the operative site, because up to now, there is no option for three-dimensional imaging of the patient with the applicator in the treatment position.

This series includes 14 patients with suspected incomplete resection in post-operative MRI. This raises the question of whether these patients were treated with an insufficient dose intraoperatively. In a similar postoperative EBRT setting, we would have treated the patient with an increased

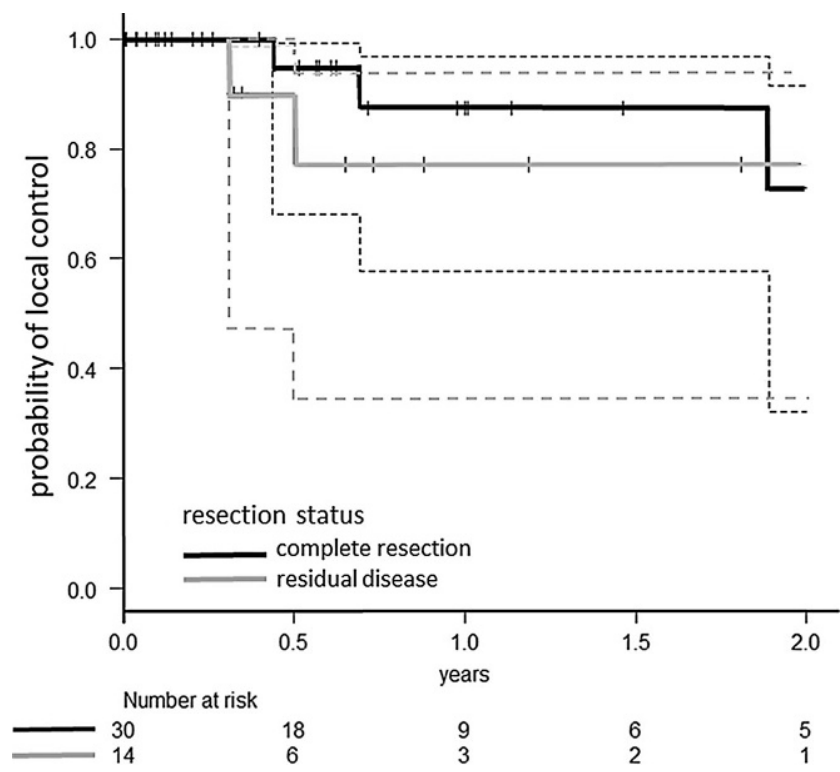

Fig. 2 Probability of local control after resection of BM and IORT stratified for complete or incomplete resection of BM in postoperative MRI (the dotted lines represent the $95 \%$ confidence intervals)

dose [2]. In our analysis, LC of patients with suspected residual disease did not significantly differ from the LC of patients with complete resection on postoperative MRI ( $87.4 \%$ versus $77.1 \%$ at 1 year $/ p=0.473$; Fig. 2 ). However, due to the limited sample size, the validity of this observation might be questioned. However, the applied biological effective dose (BED) of the IORT might be sufficient to control residual disease at the cavity walls in direct contact with the surface of the applicator. Another aspect of this issue is the observation that resection cavities after IORT tend to enhance contrast media more pronouncedly in postoperative MRI compared to cavities after surgery only. This might have led to an overdiagnosis of suspected residual disease in postoperative MRI in patients treated with IORT, blurring the correct stratification. Nonetheless, in the IORT setting, the neurosurgeon should utterly strive for complete resection of the BM.

In this series, more than half of the patients ( 21 out of 40 patients) experienced DBF after neurosurgical resection of BM and IORT. We assume this is more likely an effect of patient selection than of the specific treatment technique. One-year DBF rates in the literature vary between 20 and $70 \%$ [2, 19, 21, 22, 33-36]. Due to FU including 3-monthly MRI of the brain, all DBF of our patients were diagnosed in an asymptomatic stage. The majority of these cases could be successfully salvaged by SRS. Only $25 \%$ of all patients needed WBI due to multiple new BM or LMD in the complete further course of disease to achieve DC. The estimated LMD rate of $16.2 \%$ at 2 years in this report matches perfectly with the reported 2-year LMD rates of patients treated with focal EBRT postoperatively [33, 35, 37, 38]. 
Hence, there is no evidence that the IORT procedure affects the risk of tumor cell spillage to the cerebrospinal fluid by neurosurgery.

In this series, IORT did not increase the perioperative morbidity and mortality of neurosurgical metastasectomy or the time of hospitalization after surgery [39-41]. The observed radionecrosis $(\mathrm{RN})$ rate in our patients was $2.5 \%$. We observed RN formation only in one single case of a lesion in a pre-irradiated area. None of the non-pre-irradiated patients experienced radiologic signs of RN. In the current literature the rates of RN rage from 5 to $25 \%$ for patients treated with HSRT after resection of BM and tend to be a little higher for patients treated with SRS in the same setting [3, 18, 34, 42]. This reasonably low $\mathrm{RN}$ rate could possibly be explained by the relatively small volume of surrounding brain tissue receiving $10 \mathrm{~Gy}$ (V10), due to the steep dose gradient of LEX. V10 is an established risk factor for RN in SRS. In our series the mean applicator size was $2.0 \mathrm{~cm}$ (range $1.5-4.0 \mathrm{~cm}$ ), corresponding to a nominal mean V10 of $6.12 \mathrm{~cm}^{3}$ (range $3.08-35.95 \mathrm{~cm}^{3}$ ). Taking into account RBE, the corresponding mean V10 (RBE) is $12.97 \mathrm{~cm}^{3}$ (range $4.6-48.94 \mathrm{~cm}^{3}$ ). In this context, the combination of observed high LC and low RN rates in this series appears to be very favorable. This could only be achieved as a joint interdisciplinary effort of a multiprofessional team.

\section{Conclusion}

IORT with $50-\mathrm{kV}$ x-rays is a safe and convenient way to apply LBRT after neurosurgical resection of BM. It is associated with low toxicity and excellent LC. The IORT procedure has only a minor impact on total OR time and does not prolong the patients' recovery time in hospital. For patients with additional tumor burden, IORT LBRT holds the chance for an early start of adjacent systemic therapy. Three-monthly FU with MRI is paramount for LBRT concepts to detect the frequent distant brain failure (DBF) early. In this setting, WBI could be avoided for $75 \%$ of the patients in the further course of disease, using SRS as an effective salvage therapy for DBF.

Funding Open Access funding enabled and organized by Projekt DEAL.

\section{Declarations}

Conflict of interest K.-H. Kahl has received speaker honoraria and travel grants from ELEKTA AB, Varian Medical Systems, Carl Zeiss Meditec AG, AstraZeneca, Bristol Myers Squibb, MSD, Merck, and Medical Intelligence Medizintechnik. N. Balagiannis, M. Höck, S. Schill, Z. Roushan, E. Shiban, H. Müller, U. Grossert, I. Konietzko, B. Sommer, C.J. Maurer, A. Berlis, V. Heidecke, T. Janzen, and G. Stüben declare that they have no competing interests.
Ethical standards This research study was conducted retrospectively from data obtained for clinical purposes. It was approved by the local review board (UKA). It consists of experts of all medical disciplines involved and conforms to the provisions of the Declaration of Helsinki in 1995 (as revised in Edinburgh 2000). Consent to participate: Patients gave informed consent to the treatment and the data analysis. The statistical analysis was performed using anonymous clinical data. Consent for publication: Patients also gave informed consent to publish their data.

Open Access This article is licensed under a Creative Commons Attribution 4.0 International License, which permits use, sharing, adaptation, distribution and reproduction in any medium or format, as long as you give appropriate credit to the original author(s) and the source, provide a link to the Creative Commons licence, and indicate if changes were made. The images or other third party material in this article are included in the article's Creative Commons licence, unless indicated otherwise in a credit line to the material. If material is not included in the article's Creative Commons licence and your intended use is not permitted by statutory regulation or exceeds the permitted use, you will need to obtain permission directly from the copyright holder. To view a copy of this licence, visit http://creativecommons.org/licenses/by/4. $0 \%$

\section{References}

1. Patchell RA, Tibbs PA, Regine WF, Dempsey RJ, Mohiuddin M, Kryscio RJ, Markesbery WR, Foon KA, Young B (1998) Postoperative radiotherapy in the treatment of single metastases to the brain: a randomized trial. JAMA. https://doi.org/10.1001/jama.280.17.1485

2. Specht HM, Combs SE (2016) Stereotactic radiosurgery of brain metastases. J Neurosurg Sci 60:357-366

3. Doré M, Martin S, Delpon G, Clément K, Campion L, Thillays F (2017) Stereotactic radiotherapy following surgery for brain metastasis: predictive factors for local control and radionecrosis. Cancer Radiother 21:4-9. https://doi.org/10.1016/j.canrad.2016.06.010

4. Kocher M, Soffietti R, Abacioglu U, Villà S, Fauchon F, Baumert BG, Fariselli L, Tzuk-Shina T, Kortmann R-D, Carrie C, Hassel MB, Kouri M, Valeinis E, van den Berge D, Collette S, Collette L, Mueller R-P (2011) Adjuvant whole-brain radiotherapy versus observation after radiosurgery or surgical resection of one to three cerebral metastases: results of the EORTC 22952-26001 study. J Clin Oncol 29:134-141. https://doi.org/10.1200/JCO.2010.30. 1655

5. Brown PD, Ballman KV, Cerhan JH, Anderson SK, Carrero XW, Whitton AC, Greenspoon J, Parney IF, Laack NNI, Ashman JB, Bahary J-P, Hadjipanayis CG, Urbanic JJ, Barker FG, Farace E, Khuntia D, Giannini C, Buckner JC, Galanis E, Roberge D (2017) Postoperative stereotactic radiosurgery compared with whole brain radiotherapy for resected metastatic brain disease (NCCTG N107C/CEC.3): a multicentre, randomised, controlled, phase 3 trial. Lancet Oncol 18:1049-1060. https://doi.org/10.1016/S14702045(17)30441-2

6. Scoccianti S, Ricardi U (2012) Treatment of brain metastases: review of phase III randomized controlled trials. Radiother Oncol 102:168-179. https://doi.org/10.1016/j.radonc.2011.08.041

7. Li J, Bentzen SM, Li J, Renschler M, Mehta MP (2008) Relationship between neurocognitive function and quality of life after whole-brain radiotherapy in patients with brain metastasis. Int $\mathbf{J}$ Radiat Oncol Biol Phys 71:64-70. https://doi.org/10.1016/j.ijrobp. 2007.09.059

8. Welzel G, Fleckenstein K, Schaefer J, Hermann B, Kraus-Tiefenbacher U, Mai SK, Wenz F (2008) Memory function before and after whole brain radiotherapy in patients with and without brain 
metastases. Int J Radiat Oncol Biol Phys 72:1311-1318. https://doi. org/10.1016/j.ijrobp.2008.03.009

9. Soffietti R, Abacioglu U, Baumert B, Combs SE, Kinhult S, Kros JM, Marosi C, Metellus P, Radbruch A, Villa Freixa SS, Brada M, Carapella CM, Preusser M, Le Rhun E, Rudà R, Tonn JC, Weber DC, Weller M (2017) Diagnosis and treatment of brain metastases from solid tumors: guidelines from the European Association of Neuro-Oncology (EANO). Neuro Oncol 19:162-174. https://doi.org/10.1093/neuonc/now241

10. Scharl S, Kirstein A, Kessel KA, Duma M-N, Oechsner M, Straube C, Combs SE (2019) Cavity volume changes after surgery of a brain metastasis - consequences for stereotactic radiation therapy. Strahlenther Onkol 195:207-217. https://doi.org/10.1007/ s00066-018-1387-y

11. Guckenberger M, Baus WW, Blanck O, Combs SE, Debus J, Engenhart-Cabillic R, Gauer T, Grosu AL, Schmitt D, TanadiniLang S, Moustakis C (2020) Definition and quality requirements for stereotactic radiotherapy: consensus statement from the DEGRO/DGMP Working Group Stereotactic Radiotherapy and Radiosurgery. Strahlenther Onkol 196:417-420. https://doi.org/10. 1007/s00066-020-01603-1

12. Weil RJ, Mavinkurve GG, Chao ST, Vogelbaum MA, Suh JH, Kolar M, Toms SA (2015) Intraoperative radiotherapy to treat newly diagnosed solitary brain metastasis: initial experience and longterm outcomes. JNS 122:825-832. https://doi.org/10.3171/2014. 11.JNS1449

13. Cifarelli CP, Brehmer S, Vargo JA, Hack JD, Kahl KH, Sarria-Vargas G, Giordano FA (2019) Intraoperative radiotherapy (IORT) for surgically resected brain metastases: outcome analysis of an international cooperative study. J Neurooncol 145:391-397. https://doi. org/10.1007/s11060-019-03309-6

14. Kanda Y (2013) Investigation of the freely available easy-to-use software 'EZR' for medical statistics. Bone Marrow Transplant 48:452-458. https://doi.org/10.1038/bmt.2012.244

15. Gaspar L, Scott C, Rotman M, Asbell S, Phillips T, Wasserman T, McKenna WG, Byhardt R (1997) Recursive partitioning analysis (RPA) of prognostic factors in three radiation therapy oncology group (RTOG) brain metastases trials. Int J Radiat Oncol Biol Phys 37:745-751. https://doi.org/10.1016/S0360-3016(96)00619-0

16. Brennan C, Yang TJ, Hilden P, Zhang Z, Chan K, Yamada Y, Chan TA, Lymberis SC, Narayana A, Tabar V, Gutin PH, Ballangrud $\AA$, Lis E, Beal K (2014) A phase 2 trial of stereotactic radiosurgery boost after surgical resection for brain metastases. Int J Radiat Oncol 88:130-136. https://doi.org/10.1016/j.ijrobp.2013. 09.051

17. Combs SE, Bilger A, Diehl C, Bretzinger E, Lorenz H, Oehlke O, Specht HM, Kirstein A, Grosu A-L (2018) Multicenter analysis of stereotactic radiotherapy of the resection cavity in patients with brain metastases. Cancer Med 7:2319-2327. https://doi.org/10. 1002/cam4.1477

18. Gutschenritter T, Venur VA, Combs SE, Vellayappan B, Patel AP, Foote M, Redmond KJ, Wang TJC, Sahgal A, Chao ST, Suh JH, Chang EL, Ellenbogen RG, Lo SS (2020) The judicious use of stereotactic radiosurgery and hypofractionated stereotactic radiotherapy in the management of large brain metastases. Cancers 13:70. https://doi.org/10.3390/cancers 13010070

19. Hsieh J, Elson P, Otvos B, Rose J, Loftus C, Rahmathulla G, Angelov L, Barnett GH, Weil RJ, Vogelbaum MA (2015) Tumor progression in patients receiving adjuvant whole-brain radiotherapy vs localized radiotherapy after surgical resection of brain metastases. Neurosurgery 76:411-420. https://doi.org/10.1227/NEU. 0000000000000626

20. Scharl S, Kessel KA, Diehl C, Gempt J, Meyer B, Zimmer C, Straube C, Combs SE (2020) Is local radiotherapy a viable option for patients with an opening of the ventricles during surgical resec- tion of brain metastases? Radiat Oncol 15:276. https://doi.org/10. 1186/s13014-020-01725-x

21. Bilger A, Bretzinger E, Fennell J, Nieder C, Lorenz H, Oehlke O, Grosu A-L, Specht HM, Combs SE (2018) Local control and possibility of tailored salvage after hypofractionated stereotactic radiotherapy of the cavity after brain metastases resection. Cancer Med 7:2350-2359. https://doi.org/10.1002/cam4.1486

22. Mahajan A, Ahmed S, McAleer MF, Weinberg JS, Li J, Brown P, Settle S, Prabhu SS, Lang FF, Levine N, McGovern S, Sulman E, McCutcheon IE, Azeem S, Cahill D, Tatsui C, Heimberger AB, Ferguson S, Ghia A, Demonte F, Raza S, Guha-Thakurta N, Yang J, Sawaya R, Hess KR, Rao G (2017) Post-operative stereotactic radiosurgery versus observation for completely resected brain metastases: a single-centre, randomised, controlled, phase 3 trial. Lancet Oncol 18:1040-1048. https://doi.org/10.1016/S14702045(17)30414-X

23. Wijetunga A, Jayamanne D, Cook R, Parkinson J, Little N, Curtis J, Brown C, Back M (2020) Hypofractionated adjuvant surgical cavity radiotherapy following resection of limited brain metastasis. J Clin Neurosci 82:155-161. https://doi.org/10.1016/j.jocn.2020.10.041

24. Nardone V, Nanni S, Pastina P, Vinciguerra C, Cerase A, Correale P, Guida C, Giordano A, Tini P, Reginelli A, Cappabianca S, Pirtoli L (2019) Role of perilesional edema and tumor volume in the prognosis of non-small cell lung cancer (NSCLC) undergoing radiosurgery (SRS) for brain metastases. Strahlenther Onkol 195:734-744. https://doi.org/10.1007/s00066-019-01475-0

25. Giordano FA, Brehmer S, Abo-Madyan Y, Welzel G, Sperk E, Keller A, Schneider F, Clausen S, Herskind C, Schmiedek P, Wenz F (2014) INTRAGO: intraoperative radiotherapy in glioblastoma multiforme-a Phase I/II dose escalation study. Bmc Cancer 14:992. https://doi.org/10.1186/1471-2407-14-992

26. Vargo JA, Sparks KM, Singh R, Jacobson GM, Hack JD, Cifarelli CP (2018) Feasibility of dose escalation using intraoperative radiotherapy following resection of large brain metastases compared to post-operative stereotactic radiosurgery. J Neurooncol 140:413-420. https://doi.org/10.1007/s11060-018-2968-4

27. Liu Q, Schneider F, Ma L, Wenz F, Herskind C (2013) Relative biologic effectiveness (RBE) of $50 \mathrm{kV} \mathrm{X}$-rays measured in a phantom for Intraoperative tumor-bed irradiation. Int J Radiat Oncol Biol Phys 85:1127-1133. https://doi.org/10.1016/j.ijrobp.2012.08.005

28. Herskind C, Wenz F, Giordano FA (2017) Immunotherapy combined with large fractions of radiotherapy: stereotactic radiosurgery for brain metastases-implications for intraoperative radiotherapy after resection. Front Oncol 7:147. https://doi.org/10.3389/fonc. 2017.00147

29. Herskind C, Wenz F (2009) Is there more to Intraoperative radiotherapy than physical dose? Int J Radiat Oncol Biol Phys 74:976-977. https://doi.org/10.1016/j.ijrobp.2009.02.042

30. Wilke L, Andratschke N, Blanck O, Brunner TB, Combs SE, Grosu A-L, Moustakis C, Schmitt D, Baus WW, Guckenberger M (2019) ICRU report 91 on prescribing, recording, and reporting of stereotactic treatments with small photon beams: statement from the DEGRO/DGMP working group stereotactic radiotherapy and radiosurgery. Strahlenther Onkol 195:193-198. https://doi.org/10. 1007/s00066-018-1416-x

31. Herskind C, Griebel J, Kraus-Tiefenbacher U, Wenz F (2008) Sphere of equivalence - a novel target volume concept for Intraoperative radiotherapy using low-energy $\mathrm{X}$ rays. Int J Radiat Oncol Biol Phys 72:1575-1581. https://doi.org/10.1016/j.ijrobp.2008.08. 009

32. Uhlig S, Wuhrer A, Berlit S, Tuschy B, Sütterlin M, Bieback K (2020) Intraoperative radiotherapy for breast cancer treatment efficiently targets the tumor bed preventing breast adipose stromal cell outgrowth. Strahlenther Onkol 196:398-404. https://doi.org/ 10.1007/s00066-020-01586-z 
33. Keller A, Doré M, Cebula H, Thillays F, Proust F, Darié I, Martin S-A, Delpon G, Lefebvre F, Noël G, Antoni D (2017) Hypofractionated stereotactic radiation therapy to the resection bed for intracranial metastases. Int J Radiat Oncol Biol Phys 99:1179-1189. https://doi.org/10.1016/j.ijrobp.2017.08.014

34. Ahmed KA, Freilich JM, Abuodeh Y, Figura N, Patel N, Sarangkasiri S, Chinnaiyan P, Yu H-HM, Etame AB, Rao NG (2014) Fractionated stereotactic radiotherapy to the post-operative cavity for radioresistant and radiosensitive brain metastases. J Neurooncol 118:179-186. https://doi.org/10.1007/s11060-014-1417-2

35. Robbins JR, Ryu S, Kalkanis S, Cogan C, Rock J, Movsas B, Kim JH, Rosenblum M (2012) Radiosurgery to the surgical cavity as adjuvant therapy for resected brain metastasis. Neurosurgery 71:937-943. https://doi.org/10.1227/NEU.0b013e31826909f2

36. Pessina F, Navarria P, Cozzi L, Tomatis S, Ascolese AM, Franzese C, Toschi L, Santoro A, De Rose F, Franceschini D, Bello L, Scorsetti M (2017) Outcome appraisal of patients with limited brain metastases (BMs) from non small cell lung cancer (NSCLC) treated with different local therapeutic strategies: a single institute evaluation. BJR 90:20170022. https://doi.org/10.1259/bjr. 20170022

37. Patel KR, Burri SH, Boselli D, Symanowski JT, Asher AL, Sumrall A, Fraser RW, Press RH, Zhong J, Cassidy RJ, Olson JJ, Curran WJ, Shu H-KG, Crocker IR, Prabhu RS (2017) Comparing preoperative stereotactic radiosurgery (SRS) to post-operative whole brain radiation therapy (WBRT) for resectable brain metastases: a multi-institutional analysis. J Neurooncol 131:611-618. https:// doi.org/10.1007/s11060-016-2334-3

38. Kerschbaumer J, Pinggera D, Holzner B, Delazer M, Bodner T, Karner E, Dostal L, Kvitsaridze I, Minasch D, Thomé C, SeizRosenhagen M, Nevinny-Stickel M, Freyschlag CF (2020) Sector irradiation vs. whole brain irradiation after resection of singular brain metastasis - a prospective randomized monocentric trial. Front Oncol 10:591884. https://doi.org/10.3389/fonc.2020.591884

39. Sankey EW, Tsvankin V, Grabowski MM, Nayar G, Batich KA, Risman A, Champion CD, Salama AKS, Goodwin CR, Fecci PE (2019) Operative and peri-operative considerations in the management of brain metastasis. Cancer Med 8:6809-6831. https://doi.org/ 10.1002/cam4.2577

40. Patel AJ, Suki D, Hatiboglu MA, Rao VY, Fox BD, Sawaya R (2015) Impact of surgical methodology on the complication rate and functional outcome of patients with a single brain metastasis. JNS 122:1132-1143. https://doi.org/10.3171/2014.9.JNS13939

41. Schmieder K, Keilholz U, Combs S (2016) The interdisciplinary management of brain metastases. Dtsch Aerztebl. https://doi.org/ 10.3238/arztebl.2016.0415

42. Bodensohn R, Hadi I, Fleischmann DF, Corradini S, Thon N, Rauch J, Belka C, Niyazi M (2020) Bevacizumab as a treatment option for radiation necrosis after cranial radiation therapy: a retrospective monocentric analysis. Strahlenther Onkol 196:70-76. https://doi.org/10.1007/s00066-019-01521-x 